\title{
Application of time domain induced polarization to the mapping of lithotypes in a landfill site
}

\author{
A. Gazoty ${ }^{1}$, G. Fiandaca ${ }^{1,2}$, J. Pedersen ${ }^{1}$, E. Auken ${ }^{1}$, A. V. Christiansen ${ }^{1,3}$, and J. K. Pedersen ${ }^{4}$ \\ ${ }^{1}$ HydroGeophysics Group, Aarhus University, Aarhus, Denmark \\ ${ }^{2}$ Department of Mathematics and Informatics, University of Palermo, Palermo, Italy \\ ${ }^{3}$ Geological survey of Denmark and Greenland (GEUS), Aarhus, Denmark \\ ${ }^{4}$ Region Syddanmark, Vejle, Denmark
}

Correspondence to: A. Gazoty (aurelie.gazoty@geo.au.dk)

Received: 15 November 2011 - Published in Hydrol. Earth Syst. Sci. Discuss.: 18 January 2012

Revised: 28 May 2012 - Accepted: 5 June 2012 - Published: 29 June 2012

\begin{abstract}
A direct current (DC) resistivity and time domain induced polarization (TDIP) survey was undertaken at a decommissioned landfill site situated in Hørløkke, Denmark, for the purpose of mapping the waste deposits and to discriminate important geological units that control the hydrology of the surrounding area. It is known that both waste deposits and clay have clear signatures in TDIP data, making it possible to enhance the resolution of geological structures compared to DC surveys alone.

Four DC/TDIP profiles were carried out crossing the landfill, and another seven profiles in the surroundings provide a sufficiently dense coverage of the entire area. The whole dataset was inverted using a 1-D laterally constrained inversion scheme, recently implemented for TDIP data, in order to use the entire decay curves for reconstructing the electrical parameters of the soil in terms of the Cole-Cole polarization model.

Results show that it is possible to resolve both the geometry of the buried waste body and key geological structures. In particular, it was possible to find a silt/clay lens at depth that correlates with the flow direction of the pollution plume spreading out from the landfill and to map a shallow sandy layer rich in clay that likely has a strong influence on the hydrology of the site. This interpretation of the geophysical findings was constrained by borehole data, in terms of geology and gamma ray logging. The results of this study are important for the impact of the resolved geological units on the hydrology of the area, making it possible to construct more realistic scenarios of the variation of the pollution plume as a function of the climate change.
\end{abstract}

\section{Introduction}

Due to the expected climate changes, there is an increasing need to develop hydrogeological models for predicting water flows in sensitive areas, such as former landfills. Indeed, it is believed that groundwater fluctuations will become more extreme in the years to come. As a consequence, it would affect the time pattern and the intensity of precipitation, yielding dry summers and more rainfall in the winter season in northern Europe (see some examples of scenarios in UK in Jackson et al., 2011 and Hulme et al., 2002). At some places where aquifers are strongly influenced by surface water, this can lead to increased groundwater recharge and to a rising groundwater table.

In Denmark, many landfills operational between 1950 and 1980 were designed without any kind of capture system underneath. More generally, landfills without impermeable layers such as clay or artificial liners (uncontrolled landfills), located on top of permeable sand, are very common in Denmark and worldwide. In the literature, some similar cases can be found (e.g. Christophersen et al., 2001), and general descriptions provided by Kjeldsen et al. (1998a,b) and Christensen et al. (1993) reported a large number of groundwater contaminations caused by landfills with insufficient leachate collection system or by old dumps with no measures to prevent leachate from entering the groundwater. Poulsen et al. (2002) explained how significant efforts have been dedicated to the development of improved landfill designs towards membrane isolation systems for protecting the landfill's surroundings. In case of percolation through the waste, the predicted changes in winter rainfall will probably 
increase the risk of leaching of contaminants, which would, in turn, increase the outwash of chemical components from landfills to nearby aquifers. Landfills without leachate collection systems thus provide a high risk to future groundwater quality due to changes in groundwater level. In the light of these potential implications, it is important to have a fast, cheap and reliable technique, which is able to depict the sub-surface at high resolution, both in landfill areas and surroundings, and, if present, gain information on pollution patterns. Such a technique involves the capability of characterizing waste deposits, but also the mapping and identification of different geological units.

Two ground geophysical methods, direct current (DC) resistivity and time domain induced polarization (TDIP or more commonly IP), have shown a good complementarity in that respect. The electrical conductivity of porous rocks varies with their water content, ion concentration, mobility and the volume and arrangement of the pores (Kirsch, 2006). It increases with the conductivity of their pore fluids, as well as higher saturation degree and fractional pore space. The surface conductivity becomes important for materials with very large inner rock surfaces, such as clays (Kruschwitz and Yaramanci, 2004). The specific electrical behaviour of clay is usually explained by the presence of an external layer of cations in the so-called electrical double layer (EDL, see Revil and Glover, 1997 and Revil and Leroy, 2004) at the surface of clay particles (platelets). The cations can easily move tangentially to the surface, and the resulting surface conductivity contributes, together with the water volume conductivity, to the total conductivity (Tabbagh and Cosenza, 2007). Geophysical surveys have shown that the contribution of the surface conductivity associated with clay minerals is often the dominant term in vadose and phreatic zones characterized by low mineralized waters (Worthington, 1982).

The induced polarization method has been used increasingly in environmental investigations, because IP measurements are very sensitive to the low frequency capacitive properties of rocks and soils (Chen et al., 2008). These properties are associated with diffusion-controlled polarization processes that occur at the mineral-fluid interface (Slater and Lesmes, 2002). The IP phenomenon is often observed in media with electrical resistivities typically lying between 50 and $100 \Omega \mathrm{m}$ (the most common values for soils; see Michot et al., 2003) and containing a significant but non-dominant clay phase (Tabbagh et al., 2009). Usually, DC resistivity and IP are used jointly in order to discriminate between materials displaying a comparable signature in resistivity (e.g. brackish water and clay). Slater and Glaser (2003) showed from the results of crosshole electrical imaging performed on sandy sediments that high-resolution IP measurements might be used for a lithological description, allowing a differentiation between silt/clay and sands of different grain size. Kemna et al. (2004) used the IP method in crosshole surveys in order to make a lithological characterization and to detect hydrocarbons. They also show how IP can significantly improve the understanding of the engineering properties of the subsurface relative to resistivity imaging alone. Recently, Auken et al. (2011), Gazoty et al. (2011), and Leroux et al. (2010) have shown how the combined use of DC-TDIP could be successfully applied to landfill mapping and characterization, as it usually depicts the waste layer with a relatively high chargeable unit.

This study aims at delineating and characterizing the decommissioned Hørløkke landfill and the waste body with high accuracy. It also shows how the joint application of DC resistivity, IP and gamma ray logging enables a lithological description of the local area to be constructed and depicts different geological layers with variable clay content at high resolution.

\section{The Hørløkke area}

In the CLIWAT project, a test site has been selected for the study of a typical Danish landfill and the surrounding geology by geophysical methods, as input to improve the knowledge for further modelling studies of hydrogeology and climate change scenarios. The area of interest is a decommissioned landfill, active from 1968 to 1978. It is located in the vicinity of Vojens, in southern Denmark (Fig. 1a), and covers an approximate area of $10000 \mathrm{~m}^{2}$. The total amount of waste deposited is estimated to be $65000 \mathrm{~m}^{3}$ (Pedersen et al., 2009), mainly consisting of domestic waste and sludge from the Vojens wastewater treatment plant. Because the site was uncontrolled from 1972, some chemical waste from a refrigerator factory has also been dumped, but the amount remains unclear. The landfill was established without any kind of membrane, leachate capture or isolation systems. All waste was dumped on the original terrain, yielding a hillock approximately $15 \mathrm{~m}$ high. A number of deep boreholes present within and outside the landfill area allowed the collection of water samples up to $60-70 \mathrm{~m}$ depth. These samples revealed a contamination plume as a consequence of percolation through the landfill. The contamination has been detected below the landfill itself, and extending $500 \mathrm{~m}$ west as a deep contamination plume (50-60 m depth). At the landfill, the contamination is mainly composed of hydrocarbons, iron and inorganic compounds, as well as a small amount of percolating chlorinated compounds. Within the plume, the contamination is composed of a high concentration of volatile chlorinated compounds and inorganic parameters (potassium, sodium, calcium, chloride, etc.). The concentration of chlorinated compounds is shown in an east-west cross-section in Fig. 2, after Sønderjyllands Amt (2007) and Pedersen (2011). Note that the elevation in the figures refers to metres above the sea level (m a.s.l.).

The Hørløkke landfill is located on a small outwash plain in a topographic low. The general geology consists of gravel and sand deposits, with local interbedded moraine clay layers (Fig. 3). At the landfill itself, the top layer consists of a 2-3 m 


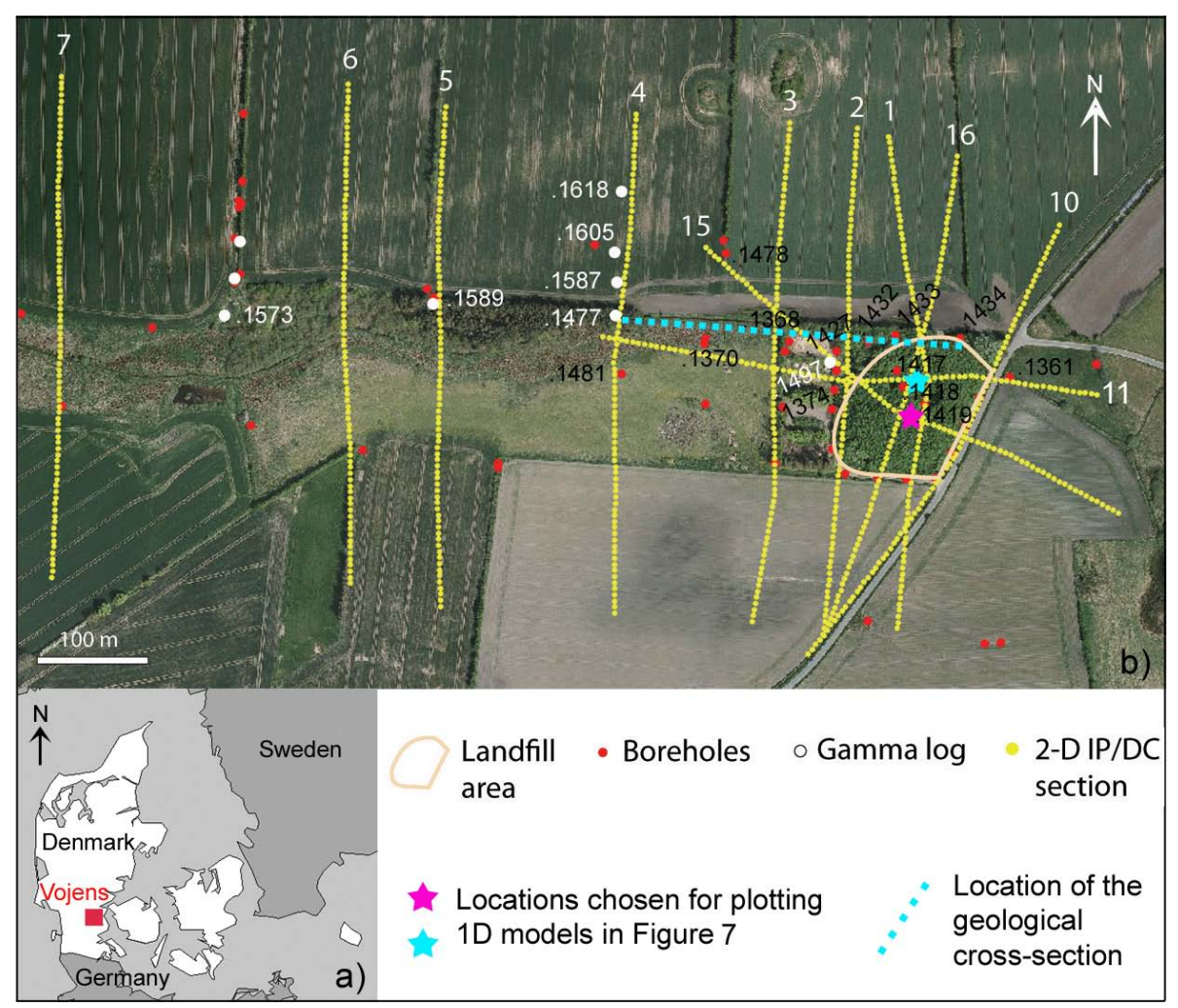

Fig. 1. The survey area. (a) Location of Vojens in the southern part of Denmark. (b) IP/DC sections (yellow dots) performed at the Hørløkke landfill (yellow area). The red dots point out the boreholes; the white dots refer to gamma log locations, and the dashed line fits the geological cross-section. The location of the watershed is about $1.5 \mathrm{~km}$ east of the map. Copyright Cowi ${ }^{\circledR}$.

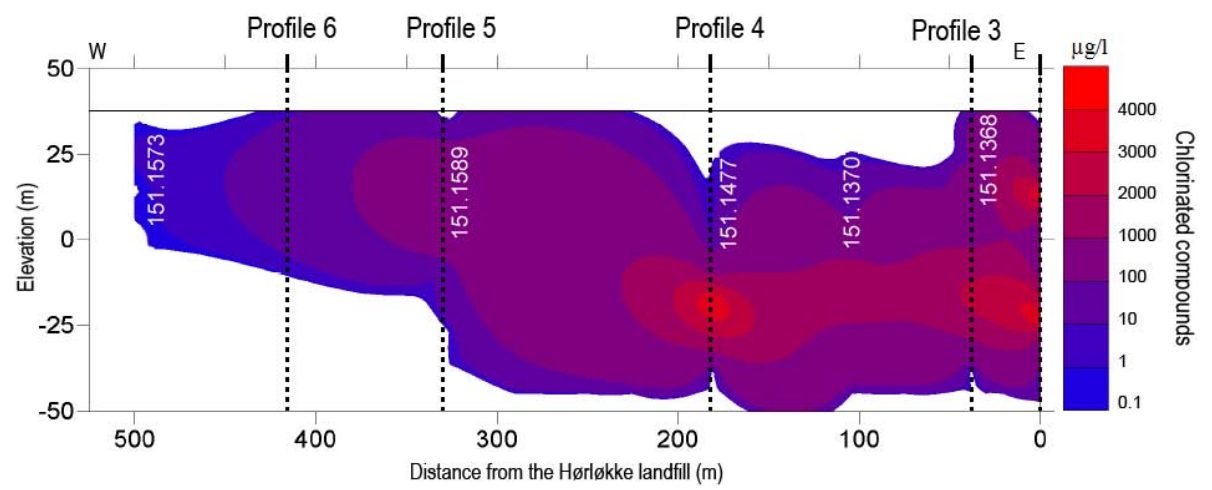

Fig. 2. Cross-section of the contaminated plume. Concentration levels refer to the total sum of chlorinated compounds. Dashed lines show the locations where the profiles cross the plume and the different numbers refer to deep boreholes (Fig. 1). Modified from Pedersen (2011).

thick clay filling layer, which covers the approximately 6$8 \mathrm{~m}$ thick waste layer.

From a hydrological point of view, the sequence of sand layers (see Fig. 3) constitutes a regional aquifer below the landfill. The aquifer thickness reaches $100 \mathrm{~m}$ in some places, and the water level is shallow, within $2-3 \mathrm{~m}$ depth. The area around the landfill has been pointed out as a special drinking water and extraction area for Vojens waterworks (Pedersen et al., 2009). The landfill lies just west of the watershed, which means there is no risk for the drinking water with the current location. However, climate change could involve the shift of the watershed further east, so that the contamination from the Hørløkke area might influence the water capture zone of the Vojens waterworks. In terms of water management context, because drinking water in Denmark is entirely based on groundwater, the Hørløkke case is quite typical, as many landfills are located in areas where the groundwater is used for water supply (see Christensen et al., 2001). 


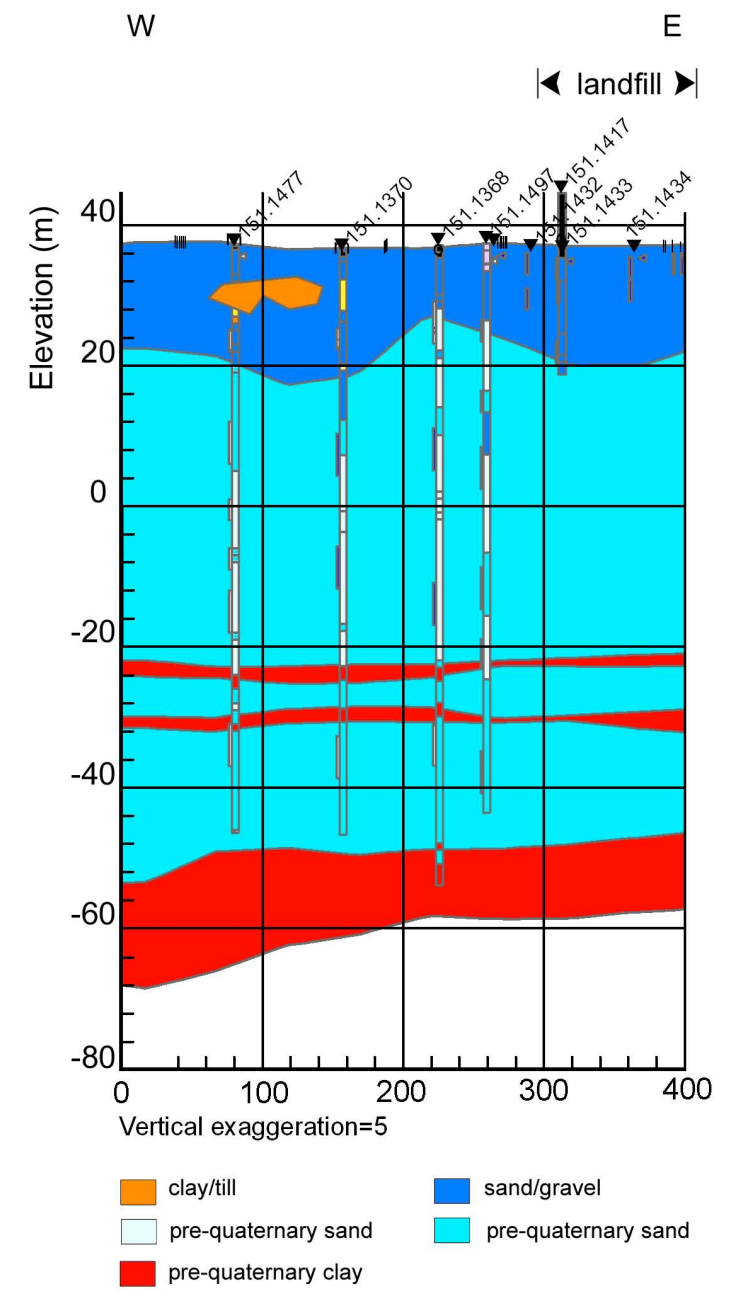

Fig. 3. Simplified geological cross-section (see location in Fig. 1). The glacial sands (shallow dark blue layer) host a regional aquifer. Modified from Pedersen et al. (2009).

This is why, and in our case particularly, an initial hydrogeophysical characterization investigation is needed, as input to constrain the geological models and predict the different likely scenarios with the highest accuracy.

\section{Materials and methods}

\subsection{DC and TDIP}

The TDIP method measures the voltage decay induced by the turn-off of an exciting current pulse (see Fig. 4) and uses the characteristics of the decay to study the induced polarization of the soil, also known as chargeability. The equipment used in the field is the same as used for DC measurements, and thus the set-up consists of potential and current electrodes equally distributed along a profile. Immediately after the current is turned on, an induced potential, $V_{\mathrm{i}}$, raises across the potential electrodes. After a charge-up effect, the primary voltage, $V_{\mathrm{DC}}$, is measured for the computation of the DC resistivity just before the current is turned off.

When the current is turned off, the voltage drops to a secondary level, $V_{\mathrm{s}}$, and then decays with time during the relaxation period. This decay curve is the target of the time domain IP method, because it is characteristic of the medium in terms of initial magnitude, slope and relaxation time. The signal $V_{\text {ip }}$ along the decay is usually integrated over $n$ time windows, or gates, for the computation of the chargeability $M$, which is expressed as following (Schön, 1996; Slater and Lesmes, 2002):

$M_{i}=\frac{1}{V_{\mathrm{DC}} \cdot\left[t_{i+1}-t_{i}\right]} \int_{t_{i}}^{t_{i+1}} V_{\mathrm{ip}} \mathrm{d} t$

where $V_{\mathrm{DC}}[\mathrm{V}]$ is the potential used for calculating the DC resistivity, $V_{\mathrm{ip}}$ is the intrinsic or secondary potential $[\mathrm{mV}]$, and $t_{i}$ and $\mathrm{t}_{i+1}$ are the open and close times [s] for the gate over which the signal is integrated.

\subsection{Inversion scheme for DC-IP data}

The inversion scheme used in this study enables the spectral content of the chargeability phenomenon to be extracted from time domain measurements. This spectral information is contained in the time decays, and its description is obtained using the Cole-Cole model (Pelton et al., 1978). The ColeCole model includes the DC resistivity $(\rho)$ and parameters describing the frequency dependency $\left(c, \tau\right.$ and $M_{0}$; see the section below for further explanation). For each profile the whole dataset was inverted following Fiandaca et al. (2012), where the time domain forward response is computed via a Hankel transform of the frequency domain response for a layered medium. Then, inversion is carried out with a 1-DLCI implementation (Auken et al., 2005) to retrieve the four Cole-Cole parameters for each layer. In the 1-D-LCI inversion algorithm, the model is composed of a set of laterally constrained 1-D models aligned along a profile (Auken et al., 2005). In practice, the LCI algorithm works by dividing a profile into several individual 1-D models, with one dataset for each model. The model parameters of layers are tied together laterally by claiming identity between neighbouring parameters within a specified variance (Auken et al., 2002), as illustrated schematically in Fig. 5.

\subsection{The Cole-Cole model}

Numerous models exist for describing the complex resistivity response of rocks and soils. These models can be classified into two: (1) the microscopic models that explain from a chemical and physical point of view the phenomenon, for instance the so-called electrical double layer model (e.g. Leroy et al., 2008), or the throat models (e.g. Titov et al., 2002), and (2) the empirical models, among which the Cole-Cole model (Cole and Cole, 1941), the Davidson-Cole model (Davidson 


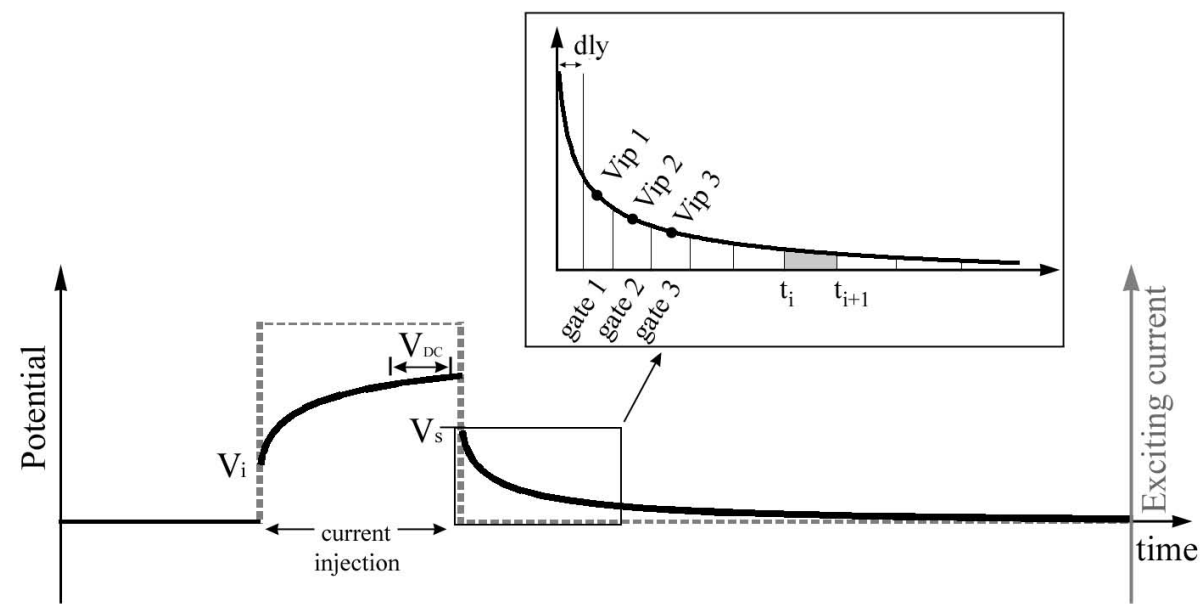

Fig. 4. Basic principles of time domain IP acquisition. The figure shows a sketch of the exciting current and the resulting voltage.

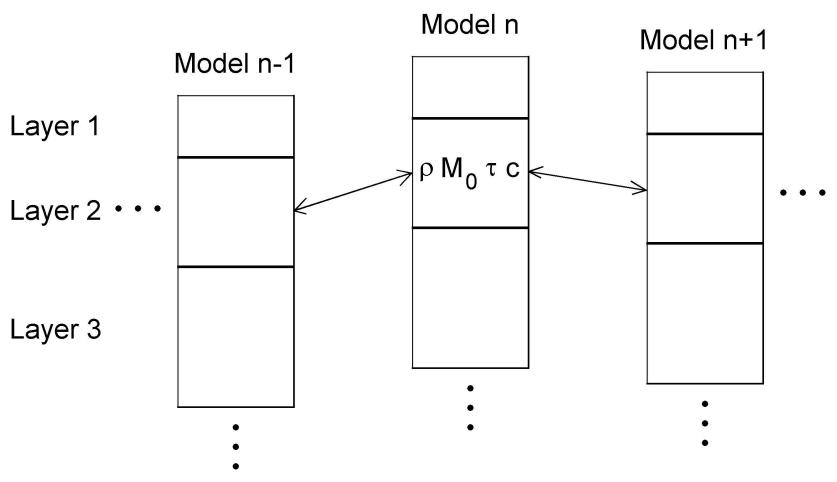

Fig. 5. Laterally constrained inversion (LCI) model set-up. The arrows represent the lateral constraints. From Fiandaca et al. (2012).

and Cole, 1950) and the constant-phase-angle (CPA) model (e.g. Van Voorhis et al., 1973) are examples. The Cole-Cole model is the most popular for field application, and it is used by Pelton et al. (1978) to describe complex resistivity in a wide range of soil types. In the time domain, Pelton et al. (1978) showed that the intrinsic chargeability curves for Cole-Cole models in homogeneous media can be described by

$M(t)=M_{0} \sum_{n=0}^{\infty} \frac{(-1)^{n}\left(\frac{t}{\tau}\right)^{n c}}{\Gamma(1+n c)}$

where $\tau$ [s], $c$ [dimensionless] and $M_{0}[\mathrm{mV} / \mathrm{V}]$ are the ColeCole decay parameters. $M_{0}$ is the magnitude of the chargeability taken at $t=0 ; \tau$ is a time constant that characterizes the decay, and $c$ is a constant that controls the frequency dependence and is bounded between the values of 0.0 and 1.0; $\Gamma$ is the gamma function. In terms of physical properties, $M_{0}$ describes the magnitude of the polarization effect, and $\tau$ the relaxation time, indicating, in the frequency domain, the position of the phase peak. Pelton et al. (1978) and Luo and Zhang (1998) showed that $M_{0}$ and $\tau$ depend on the quantity of polarizable elements and their size, respectively, whereas $c$ depends on the size distribution of the polarizable elements (Vanhala, 1997; Luo and Zhang, 1998).

\subsection{Borehole gamma ray logging}

Since 1990, more than 25 boreholes with a depth of about $85 \mathrm{~m}$ have been established near the landfill site (Fig. 1) by reverse air rotary drilling for the collection of water samples and for providing a thorough lithological description. Geophysical logging (natural gamma, induction, resistivity) has been performed in half of the boreholes before casing. Each borehole was equipped with 4-6 screens over the depth from approximately 10 to $80 \mathrm{~m}$ below surface.

The gamma ray logging (hereafter referred to as gamma $\log$ ) measures the natural gamma radiation emanating from a formation. The major natural radioelements that contribute to the measured gamma radiation are thorium, uranium and potassium (e.g. Adams and Gasparini, 1970). Although there is no fixed rule regarding the amount of radioactivity for a given rock, shales, clays and marls are generally several times more radioactive than clean sands, sandstones, limestones and dolomites. The gamma log is extremely useful, especially to discriminate among the different lithologies because of its high vertical resolution. Clays are usually sufficiently high in radioactivity, because their cation exchange capacity (CEC) allows adsorbing uranium and thorium. As a consequence, they can generally be easily distinguished from the other rock formations on a gamma log.

Such type of borehole information is extremely useful to validate the results from surface measurements. In this study, borehole descriptions were superimposed to the 2-D sections to check the consistency of the results, but no a priori information was integrated to the inversion. 

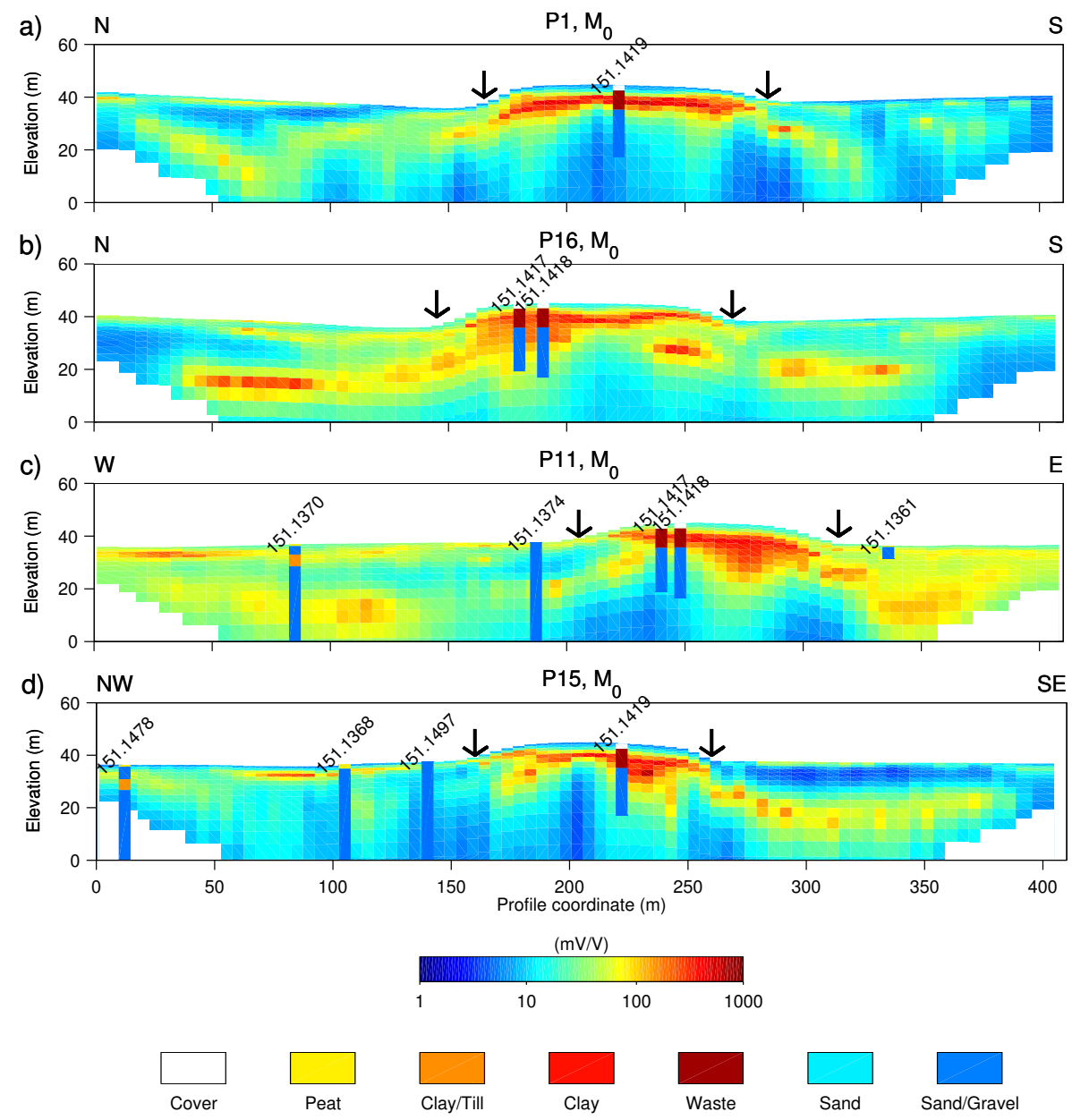

Fig. 6. Inverted sections in chargeability crossing the landfill with superimposed boreholes. The landfill is located within the arrows. High chargeability is coloured red.

\section{The survey}

The area was investigated with the collection of 11 IP/DC sections totalling $410 \mathrm{~m}$, both on top of the landfill and in the surroundings, all with an electrode spacing of $5 \mathrm{~m}$ (Fig. 1b). The survey was performed using the gradient array (Dahlin and Zhou, 2006), which was implemented on a SYSCAL-Pro instrument (Iris Instruments). The on- and off-time lengths for the time decay measurements were set to $4 \mathrm{~s}$. The data were acquired using logarithmically spaced gates (Effers $\varnothing$ et al., 1999) with approximately eight gates per decade, with a total of 20 gates. Four sections have been performed on the landfill itself, all exceeding the landfill boundaries in order to cover both areas of low signal and expected high signal. Six other profiles are located either at the edge of the landfill or within the contaminated area, and one profile was set up outside the contaminated area to infer whether any different signature in IP/DC could be detected.

\section{Results}

\subsection{Landfill mapping}

The inversion results for the four sections crossing the landfill are presented in Fig. 6. Because of the relevance of the parameter $M_{0}$ for depicting landfill areas, as shown by Auken et al. (2011), it was chosen in this section to show the results from this parameter only. Within the landfill area, the chargeability model can be divided into three layers. The first layer on top is 3 to $5 \mathrm{~m}$ thick, with a chargeability of roughly $10 \mathrm{mV} \mathrm{V}^{-1}$. Underneath, the second layer of $5-20 \mathrm{~m}$ thickness displays a high chargeability signal up to $500 \mathrm{mV} \mathrm{V}^{-1}$. The third deep layer in the model has a rather uniform chargeability of $10-30 \mathrm{mV} \mathrm{V}^{-1}$. These chargeability units show a good agreement with the boreholes. The first layer of $10 \mathrm{mV} \mathrm{V}^{-1}$ in the topsoil agrees with a clay filling layer present in the boreholes. The third layer in the chargeability model more likely fits a sand layer (again, the top boundaries of the geological units and the model are completely 

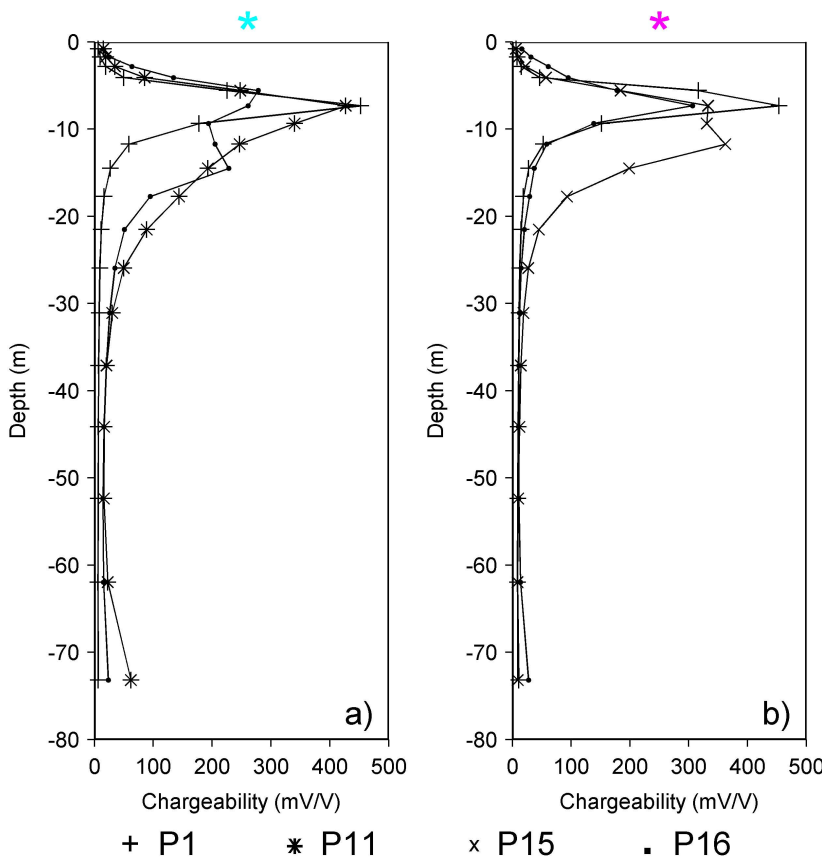

Fig. 7. Extracted models from the inverted surface measurements crossing the landfill. The stars refer to the locations on the map in Fig. 1. (a) 1-D models from profiles 1, 11 and 16. (b) 1-D models from profiles 1,11 and 15 .

consistent between each other), which is responsible for the low chargeability signal from 20 to $50 \mathrm{mV} \mathrm{V}^{-1}$ only. The high chargeable unit in between, of several hundreds of $\mathrm{mV} \mathrm{V}^{-1}$ at $5-10 \mathrm{~m}$ depth, is laterally bounded within the anticipated landfill. Its depth and thickness reasonably fit the waste body revealed by the boreholes. Although inverted separately and independently (without any spatial constraints), the information content provided by the four inverted sections is very consistent between each other. Note that the high chargeable features on either side of the landfill, going down to depth, are most likely due to some topographic effects, as explained by Fox et al. (1980), and are therefore of no consequence to the interpretation in this study.

Figure 7 shows 1-D models in chargeability $M_{0}$, from the inverted profiles P1, P11, P15 and P16, at two locations where they roughly cross each other (cf. stars in Fig. 1b). At each intersection, there is an acceptable match between the sections, in terms of depth, thickness and signal magnitude. A clear distinctive unit reaching $300-450 \mathrm{mV} \mathrm{V}^{-1}$ enhances the waste layer at about $10 \mathrm{~m}$ depth. These results agree with Auken et al. (2011), Leroux et al. (2010) or Carlson et al. (2001), who report a high chargeable unit related to the waste bodies.

Because of the dense coverage of data across the landfill area and a good fit between all sections, it is possible to map and characterize the former landfill boundaries with a high accuracy, both in terms of thickness and lateral extent.

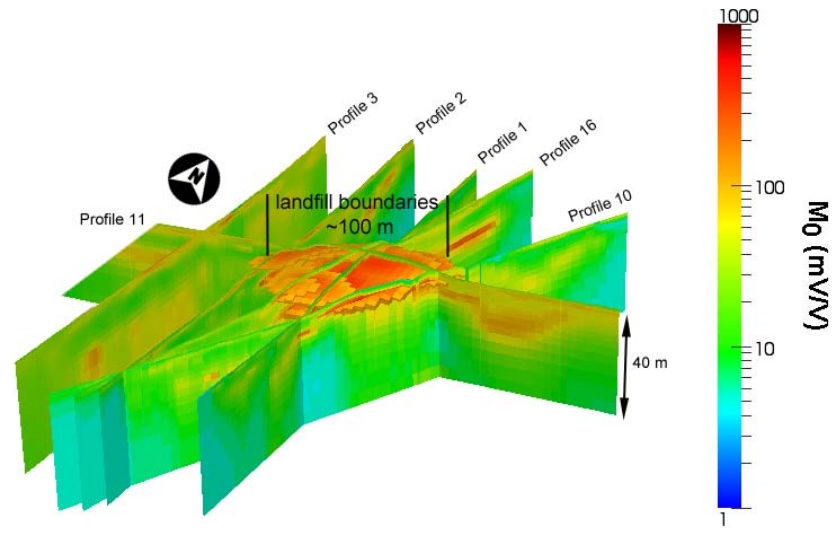

Fig. 8. 3-D chargeability plot of the Hørløkke landfill. The isovolume map with chargeability $\left(M_{0}\right)$ above $100 \mathrm{mV} \mathrm{V}^{-1}$ allows depicting the landfill area without ambiguity.

Figure 8 shows gathered 2-D sections in $M_{0}$ crossing and bounding the landfill. It shows a good agreement between crossing profiles, as well as a strong contrast in $M_{0}$ between the dump site and the close surrounding area (around 50 times higher). In order to quantify the extent of the waste layer, an isovolume rendering of chargeability encompassed between $100-500 \mathrm{mV} \mathrm{V}^{-1}$ was added to the sections by following the method in Pryet et al. (2011), who developed a 3 -D gridding for 1-D resistivity models. The range of chargeability was chosen, because this is the signal level characterizing the waste body (as seen in Fig. 7). The isovolume with high chargeability is $50000 \mathrm{~m}^{3}$ large, which is in the same range of the a priori knowledge of the waste dumped in the landfill (65 $000 \mathrm{~m}^{3}$, after Pedersen et al., 2009).

\subsection{Soil type discrimination}

We have seen in the previous section that the induced polarization method is able to map and characterize the landfill. Several profiles were performed in addition outside the landfill area in order to improve the geological description and clarify the presence of some specific patterns such as potential clay lenses, both in the shallow and deeper parts. Indeed, from Fig. 3 it appears that some clay layers are expected at 50-60 m depth, but the exact location in terms of depth and lateral extent remains unclear. It is, however, very important to gain knowledge of the geological description in order to improve the hydrogeological models and understand the flow pattern of the pollution plume. Care was taken to place the profiles on top of boreholes where possible, in order to correlate the information content provided by both methods. Results from profile 4 are presented in Fig. 9 with superimposed boreholes, with one section for each inversion parameter $(\rho$, $M_{0}, c$ and $\tau$ ). This profile is representative of the main resistivity/chargeability features present in the other profiles carried out in the landfill surroundings, and the geological 

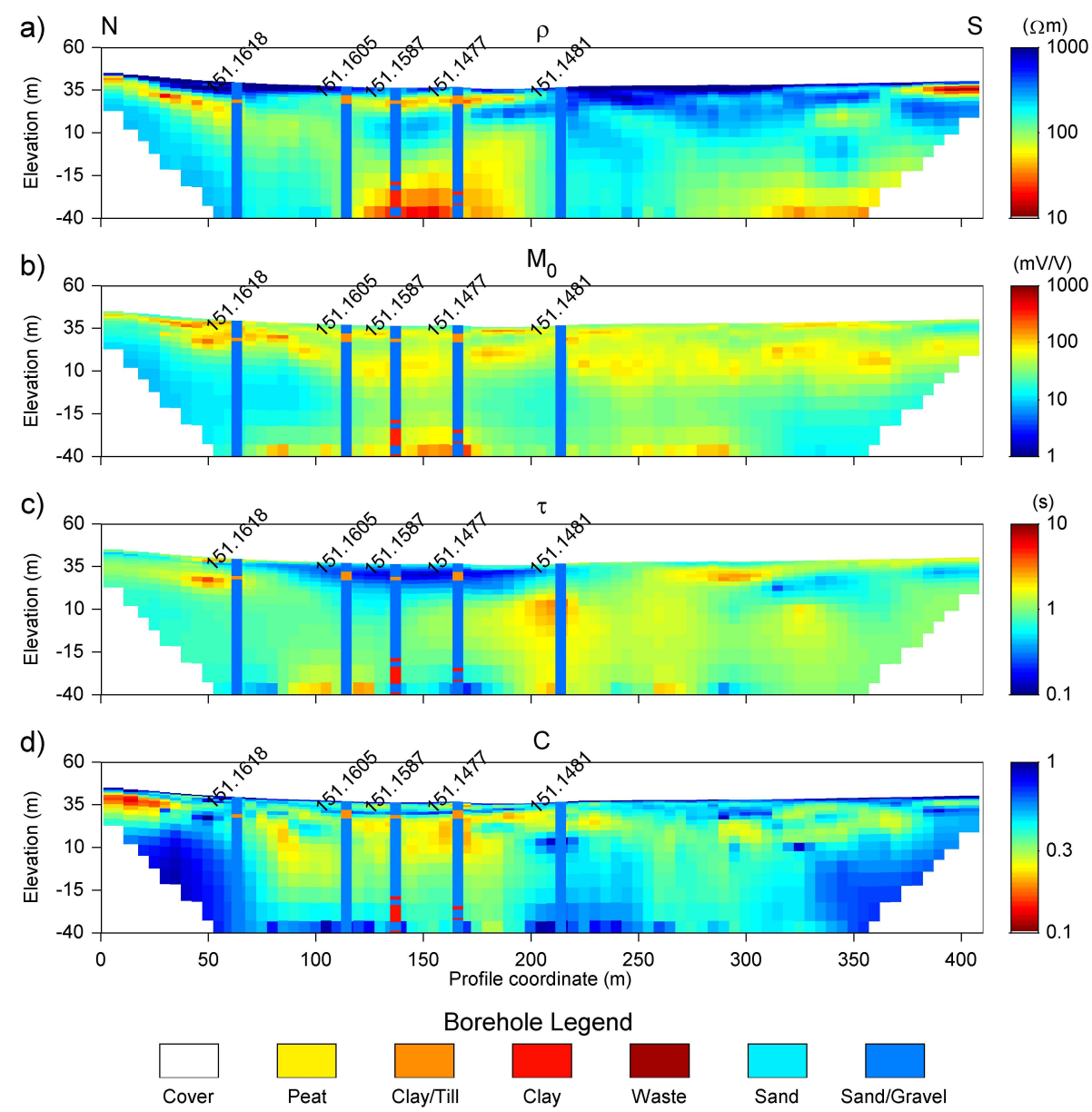

Fig. 9. Inverted sections for profile 4 (see location on the map Fig. 1) with superimposed boreholes. (a) Resistivity section, (b) Chargeability $M_{0}$, (c) $\tau$ parameter, (d) $c$ parameter.

interpretation of the geophysical inversions is presented in the next sections.

\subsubsection{Creek aquitard}

In profile 4 , within $120-200 \mathrm{~m}$ from the north, a shallow conductive lens of about $60 \Omega \mathrm{m}$ is present at $5-10 \mathrm{~m}$ depth (Fig. 9a). This lens is seen as a high chargeable layer of $80 \mathrm{mV} \mathrm{V}^{-1}$ (Fig. 9b), and fits the clay-till layer (in orange) revealed by boreholes $151.1605,151.1587$ and 151.1477 . A slight vertical shift is observed between the chargeability $M_{0}$ and the clay lens present in boreholes, which can be easily due to a difference of resolution of the inversion parameters. Figure 10 shows a comparison between gamma logs performed in boreholes $151.1618,151.1605$, and 151.1587, and 1-D models of resistivity and chargeability close to boreholes. Figure 10a shows a reasonable fit within 5-10 m depth, between the IP signal (high signal magnitude) and the gamma log, which displays a high peak signal of $40 \mathrm{cps}$. In addition, Fig. 10b shows that a low resistive layer is present at this depth, which is anti-correlated with the gamma log.
The concordance of low resistivity/high chargeability with a high gamma log reinforces the presence of a clay layer. The dense coverage in IP/DC enables to define the lateral extent of this lens, observed from profiles 6 to 16. Again, there is a good match in resistivity and chargeability where the 2-D sections cross each other (e.g. between profiles 4 and 11). This clay layer underlies the Billund Creek, which runs just north of the borders of the landfill, in the east-west direction. Thus, this layer is probably an aquitard, acting as a bed of low permeability along the aquifer.

\subsubsection{Clay rich sandy layer}

A moderately chargeable anomaly of $50-100 \mathrm{mV} \mathrm{V}^{-1}$ is present in the $M_{0}$ section of profile 4 at $20-40 \mathrm{~m}$ depth. This anomaly cannot be explained by the geological description of the boreholes, which reports the soil at this depth only in terms of sand. However, the signal level is present with different extents in all the other profiles of the survey. As a matter of fact, purely sandy soil usually does not show high chargeability, and consequently, no high values 

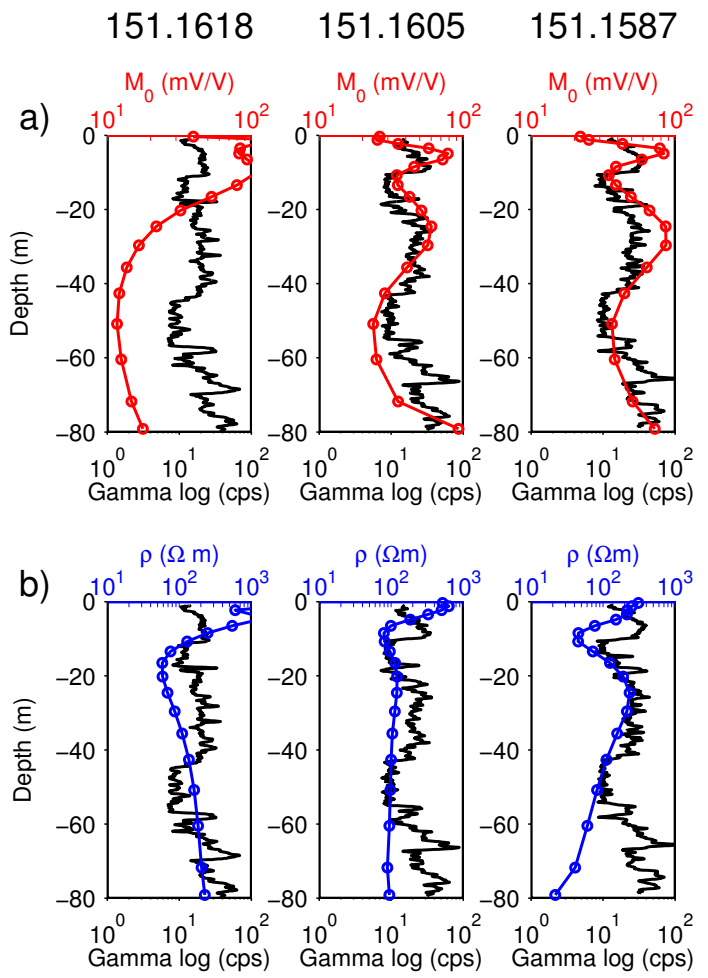

Fig. 10. Gamma logs (black) in comparison with 1-D inversion models derived from surface measurements for Profile 4. (a) Chargeability M0. (b) Resistivity. The names of boreholes are specified on the map Figure 1.

for $M_{0}$. Figure 10a shows, between 20 and $40 \mathrm{~m}$ depth, a high chargeable layer fitting a high gamma radiation for boreholes 151.1605 and 151.1587. At this depth, Fig. 10b shows a high resistive content contrary to the shallower part, which is conductive. High gamma log and high chargeability usually indicate a significant clay content, but in this case the resistivity method enables to discriminate a pure clay layer, which is expected to be conductive (as observed shallower; see paragraph above), and a clay rich sandy layer, which is more resistive, as found between 20 and $40 \mathrm{~m}$ depth. This example demonstrates the complementarity of IP, DC resistivity and gamma log, as the joint application of these three methods allows a detailed recognition of the different geological formations.

\subsubsection{Deep silt/clay lens}

Within 125-200 $\mathrm{m}$ from the north, profile 4 in Fig. $9 \mathrm{~b}$ shows a more conductive feature at depth, reaching the basis of the section. This conductive bulk also can be observed in the raw data. Considering a $400 \mathrm{~m}$ profile with $5 \mathrm{~m}$ takeouts, the depth of the feature remains on the ability of the DC method. This body can be considered as a true and reliable pattern, even though it is located at depth. In addition, a conductive deep anomaly is present in all the other profiles going to the west, except profile 7. Figure 11 shows a 3-D plot of the resistivity models for all sections, with an isovolume in resistivity lower than $100 \Omega \mathrm{m}$. This isovolume enhances a pattern, which is near the surface in the vicinity of the landfill, dips to the west and vanishes before profile 7. Overall, the shape of this body has an extent of roughly $350 \mathrm{~m}$ and, at some places, a width of $120 \mathrm{~m}$. The deeper part of this conductive anomaly fits well with silt/clay content in boreholes as also shown in Fig. 9.

Based on chlorinate compounds contained in boreholes, it is known that a contamination plume is present in the area, running west from the landfill because of the direction of the water flow. The extent of the contamination plume is roughly outlined in Fig. 11 with a purple line. The line joins the boreholes where no pollution was found and then represents the external boundary of the pollution plume. The lateral extent of the conductive isovolume is entirely comprised inside the boundary of the plume, as also shown in Fig. 11. Consequently the presence of the plume can be due to an underlying silt/clay lens that lowers the hydraulic permeability in the soil.

\section{Discussion}

The present study only focussed on results of the $M_{0}$ parameter, because it is the only one for which a straightforward correlation with the lithology, the waste content and borehole information is possible. Indeed, $M_{0}$ indicates how polarizable the medium is, and whether there is a signature in chargeability or not. Several papers, however, show that the normalized chargeability (i.e. the ratio between chargeability and resistivity) is a better parameter for discriminating lithotypes when compared with chargeability alone (Lesmes and Frye, 2001; Slater and Lesmes, 2002). Despite this we chose to not plot the inversion results in terms of normalized chargeability, but to show the parameters directly used in the inversion process. This is because, in this study, the parameter $M_{0}$ shows a better correlation with the gamma log when compared to the normalized chargeability. In any case, Fig. 9, for instance, presents all the information needed to derive the values of normalized chargeability by comparing the values of the inversion parameters. Contrary to Fig. 6, in Fig. 9 the inversion parameters $\rho, \tau$ and $c$ are shown for completeness. The parameter $\tau$ shows some general trends, such as a small magnitude within $50-200 \mathrm{~m}$ laterally, where the stream is located, and an increase of magnitude with depth beyond $20 \mathrm{~m}$. In Fig. 9d, high values of the parameter $c$ fit well with the clay layer, as evident in boreholes 151.1605 and 151.1587. It is known from literature that $\tau$ and $c$ are relevant parameters for providing significant information at the pore scale. They can be linked somehow with hydrogeological parameters such as hydraulic conductivity, but their use involves further modelling and analysis, which is beyond the scope of this study. In the present case, we do not have 


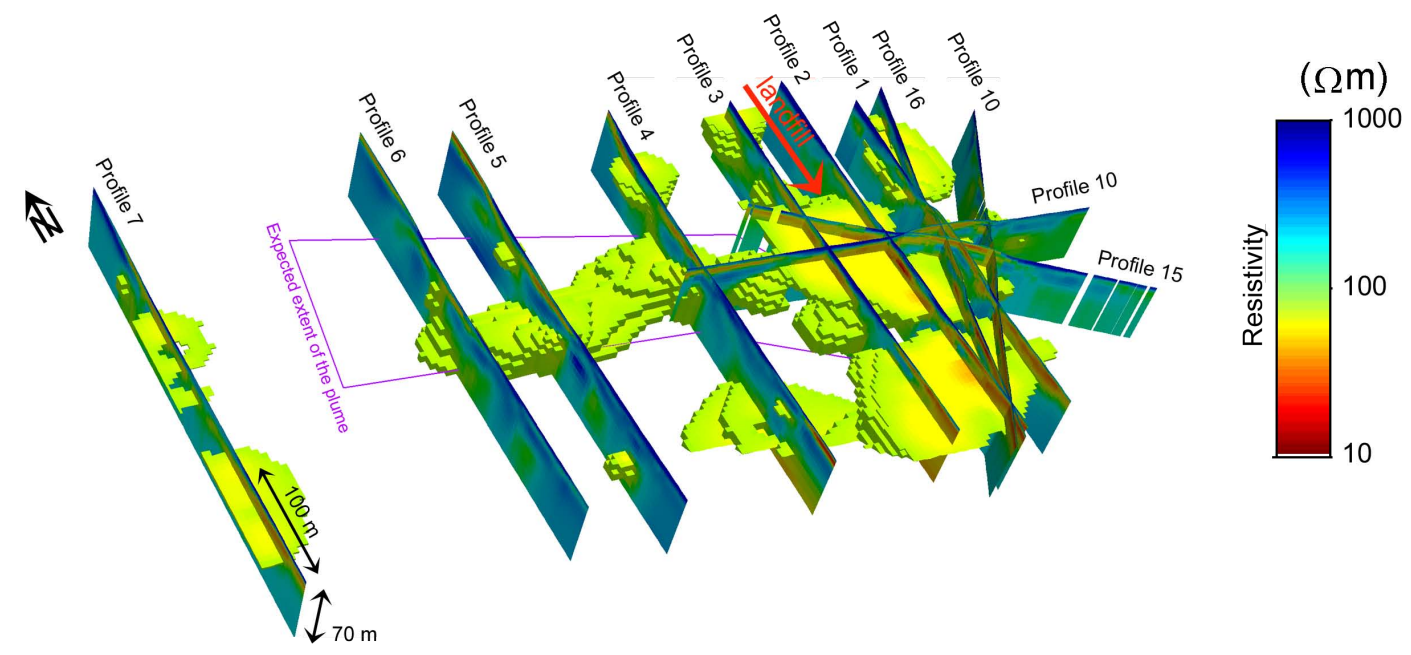

Fig. 11. Delineating the deep clay layer with the DC method: 3-D view of gathered resistivity sections with isovolume of resistivities lower than $100 \Omega \mathrm{m}$. The anticipated extent of the plume is drawn in purple.

enough information to link the observed trends in $\tau$ and $c$ with petrophysical properties.

The quality of the inverted sections presented in this paper can be attested by the perfect match between all information provided by the 2-D sections wherever they cross each other, even though each single section was inverted individually, i.e. without any spatial constraints. More importantly, the borehole information also allowed the outputs of the geophysical survey to be verified; the match between both is good, inside and outside the landfill. The boreholes were also essential for the interpretation of the geophysical results, mainly for the clay-rich sandy layer and the silt/clay lens at depth. In our experience, the new inversion scheme adopted for inverting the data also played a significant role in the success of the interpretation of TDIP data. The different geological units pointed out are then summarized in Fig. 12.

The fact that geophysical results can provide a detailed and reliable geological description is of primary importance for modelling the effects of climate changes. In the framework of the CLIWAT project, the Hørløkke area was widely investigated by different geophysical methods (Støvring et al., 2011; Foged et al., 2009; Siemon et al., 2010). Airborne EM data, together with drillings and surface measurements like pulled array continuous electrical profiling (PACEP, see Sørensen, 1996) and multiple electrode profiling (MEP), were used in order to provide a strong input for geological models, on the basis of which dynamic hydrogeological solute transport models have been run. It was shown that the combination of geological/geophysical surveys, geological modelling and hydrogeological modelling was a powerful tool for the prediction of climate change effects on the groundwater conditions (Støvring et al., 2011).

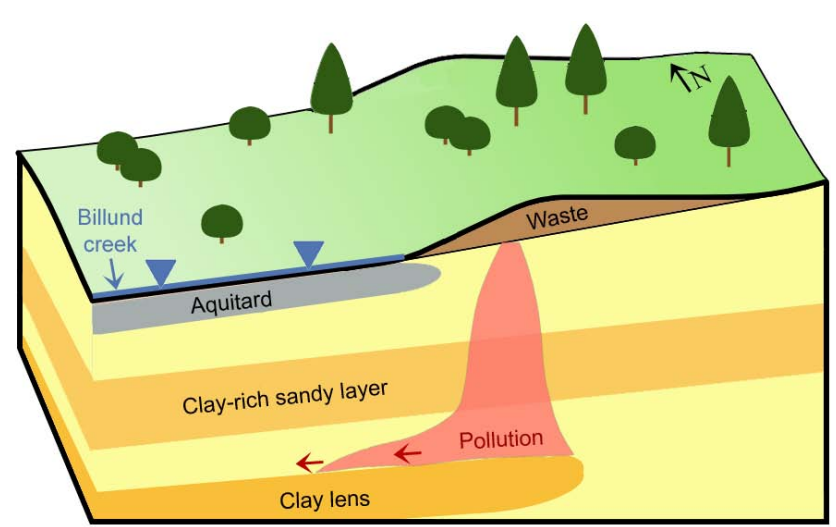

Fig. 12. Qualitative model obtained from geophysical measurements for a section crossing the landfill from west to east (not at scale).

\section{Conclusions}

The geophysical survey, together with the borehole information, allowed the recognition and spatial delineation of several geological units important for the hydrology of the area. In particular, it was possible to map three key structures that influence the water flow of the site: the clay layer just underneath the Billund Creek north of the landfill; a clay-rich sandy layer at a depth of 20-40 m that likely exhibits a different hydraulic conductivity when compared to the upper and lower clay-poor sandy soil; a silt/clay lens at depth, which extends about $350 \mathrm{~m}$ west from the landfill and that likely supports the flow of pollution in a westerly direction. The use of both DC and TDIP data, instead of DC measurements alone, greatly enhanced the resolution power of the survey not only for the landfill delineation, but also for the characterization of the creek aquitard and for the recognition of the 
clay-rich sandy layer. In particular, this last finding is noticeable, because the DC data alone did not show any evidence of the enriched clay content. These results are a good example of the potential of the IP method for hydrogeological studies and in landfill delineation, but more care is necessary in the field to obtain a good data quality in comparison with the acquisition of DC data only.

The detailed geological knowledge gained with the geophysical survey is particularly important in the investigated area, where the presence of the landfill and the related pollution plume provide a high risk for the underlying aquifer. More realistic scenarios of the variation of the outwash of chemical components from landfills to nearby aquifers, as a consequence of the climate change and modification in the groundwater level, are available when incorporating such kinds of information in the hydrogeological modelling.

Acknowledgements. This article is an outcome of the EU Interreg IVB project CLIWAT. It has been co-funded by the North Sea Region Programme 2007-2013 under the ERDF of the European Union.

This work was also supported by the Danish Agency for Science Technology and Innovation funded project RiskPoint-Assessing the risks posed by point source contamination to groundwater and surface water resources under grant number 09-063216.

Edited by: B. Siemon

\section{References}

Adams, J. A. S. and Gasparini, P.: Gamma-ray spectrometry of rocks: Elsevier Publishing Company, New York, p. 295, 1970.

Auken, E., Foged, N., and Sørensen, K. I.: Model recognition by 1-D laterally constrained inversion of resistivity data, in: Proceedings 8th meeting EEGS-ES, Aveiro, Portugal, 8-12 September 2002 .

Auken, E., Christiansen, A. V., Jacobsen, B. H., Foged, N., and Sørensen, K. I.: Piecewise 1D Laterally Constrained Inversion of resistivity data, Geophys. Prospect., 53, 497-506, 2005.

Auken, E., Gazoty, A., Fiandaca, G., Pedersen, J., and Christiansen, A. V.: Mapping of Landfills using Time-domain Spectral Induced Polarization Data - The Eskelund Case Study, 17th European Meeting of Environmental and Engineering Geophysics (Near Surface), Leicester, UK, Expanded abstracts, E14, 1214 September 2011.

Carlson, N. R., Hare, J. L., and Zonge, K. L.: Buried landfill delineation with induced polarization: progress and problems, in: Proceedings 14th meeting Symposium on the Application of Geophysics to Engineering and Environmental Problems (SAGEEP), Denver, Colorado, 4-7 March 2001.

Chen, J., Kemna, A., and Hubbard, S. S.: A comparison between Gauss-Newton and Markov-chain Monte Carlo-based methods for inverting spectral induced-polarization data for Cole-Cole parameters, Geophysics, 73, 247-258, 2008.

Cole, K. S. and Cole, R. H.: Dispersion and absorption in dielectrics, J. Chem. Phys., 9, 341-351, 1941.
Christensen, T. H., Kjeldsen, P., Albrechtsen, H.-J., Heron, G., Nielsen, P. H., Bjerg, P. L., and Holm, P. E.: Attenuation of landfill leachate pollutants in aquifers, Crit. Rev. Env. Sci. Tec., 24, 119-202, 1993.

Christensen, T. H., Kjeldsen, P., Bjerg, P. L., Jensen, D. L., Christensen, J. B., Baun, A., Albrechtsen, H.-J., and Heron, G.: Eeview: Biogeochemistry of landfill leachate plumes, Appl. Geochem., 16, 659-718, 2001.

Christophersen, M., Kjeldsen, P., and Holst, H.: Lateral gas transport in soil adjacent to an old landfill: factors governing emissions and methane oxidation, Waste Manage. Res., 19, 595-612, doi:10.1177/0734242X0101900616, 2001.

Dahlin, T. and Zhou, B.: Multiple-gradient array measurements for multichannel 2D resistivity imaging, Near Surf. Geophys., 4, 113-123, doi:10.3997/1873-0604.2005037, 2006.

Davidson, D. W. and Cole, R. H.: Dielectric relaxation in glycerine, J. Chem. Phys., 18, 1417, doi:10.1063/1.1747496, 1950.

Effers $\varnothing$, F., Auken, E., and Sørensen, K. I.: Inversion of bandlimited TEM responses, Geophys. Prospect., 47, 551-564, 1999.

Fiandaca, G., Auken, E., Christiansen, A. V., and Gazoty, A.: Full decay forward response modeling and direct inversion for ColeCole parameters, Geophysics, 77, 1-13, doi:10.1190/GEO20110217.1, 2012.

Foged, N., Roth, B., Christiansen, A. V., and Auken, E.: SkyTEM kortlægning - Sommersted Status rapport, Geologisk Institut, Aarhus University, 2009.

Fox, C. R., Hohmann, G. W., Killpack, T. J., and Rijo, L.: Topographic effects in resistivity and induced polarization surveys, Geophysics, 45, 75-93, 1980.

Gazoty, A., Auken, E., Pedersen, J., Fiandaca, G., and Christiansen, A. V.: Reliability of Time domain Induced Polarization data, Symposium on the Application of Geophysics to Engineering and Environmental Problems (SAGEEP), Charleston, South Carolina, USA, 10-14 April 2011, SAGEEP 24, doi:10.4133/1.3614088, 2011

Hulme, M., Jenkins, G. J., Lu, X., Turnpenny, J. R., Mitchell, T. D., Jones, R. G., Lowe, J., Murphy, J. M., Hassell, D., Boorman, P., McDonald, R., and Hill, S.: Climate change scenarios for the United Kingdom: the UKCIP02 scientific report, Tyndall Centre for Climate Change Research, University of East Anglia, Norwich, UK, 2002.

Jackson, C. R., Meister, R., and Prudhomme, C.: Modelling the effects of climate change and its uncertainty on UK Chalk groundwater resources from an ensemble of global climate model projections, J. Hydrol., 399, 12-28, doi:10.1016/j.jhydrol.2010.12.028, 2011.

Kemna, A., Binley, A., and Slater, L. D.: Crosshole induced polarization imaging for engineering and environmental applications, Geophysics, 69, 97-107, 2004.

Kirsch, R.: Groundwater geophysics - A Tool for Hydrogeology, ISBN 3-540-29383-3, Springer, 493 pp., 2006.

Kjeldsen, P., Grundtvig, A., Winther, P., and Andersen, J. S. Characterization of an old municipal landfill (Grinsted, Denmark) as a groundwater pollution source: landfill history and leachate composition, Waste Manage. Res., 16, 3-13, doi:10.1177/0734242X9801600102, 1998a.

Kjeldsen, P., Bjerg, P. L., Rügge, K., Christensen, T. H., and Pedersen, J. K.: Characterization of an old municipal landfill (Grinsted, Denmark) as a groundwater pollution source: landfill 
hydrology and leachate migration, Waste Manage. Res., 16, 1422, doi:10.1177/0734242X9801600103, 1998b.

Kruschwitz, S. and Yaramanci, U.: Detection and characterization of the disturbed rock zone in claystone with the complex resistivity method, J. Appl. Geophys., 57, 63-79, 2004.

Leroux, V., Dahlin, T., and Rosqvist, H.: Time-domain IP and resistivity sections measured at four landfills with different contents, 16th Eurepean Meeting of Environmental and Engineering Geophysics (Near Surface), Zürich, Switzerland, Expanded abstracts, P09, 6-8 September 2010.

Leroy, P., Revil, A., Kemna, A., Cosenza, P., and Ghorbani, A.: Complex conductivity of water-saturated packs of glass beads, J. Colloid Interf. Sci., 321, 103-117, 10.1016/j.jcis.2007.12.031, 2008.

Lesmes, D. and Frye, K. M.: Influence of pore fluid chemistry on the complex conductivity and induced polarization responses of Berea sandstone, J. Geophys. Res., 160, 4079-4090, 2001.

Luo, Y. and Zhang, G.: Theory and Application of Spectral Induced Polarization, Geophysical Monograph Series No. 8, ISBN 156080-048-8, Society of Exploration Geophysicists, 171 pp., 1998.

Michot, D., Benderitter, Y., Dorigny, A., Nicoullaud, B., King, D., and Tabbagh, A.: Spatial and temporal monitoring of soil water content with an irrigated corn crop cover using surface electrical resistivity tomography, Water Resour. Res., 39, 1138, doi:10.1029/2002WR001581, 2003.

Pedersen, J: Induced polarization for three-dimensional characterization of landfills, MSc thesis 20052492, Department of Earth Sciences, Aarhus University, 2011.

Pedersen, J. K., Christensen, J. F., Poulsen, A. R., Wernberg, T., and Jacobsen, O. K.: Nedbrydning af chlorerede opløsningsmidler I en dybtliggende forureningsfane vurderet på baggrund af vandanalyser og modellering, ATV Jord og Grundvand, 71-82, 2009.

Pelton, W. H., Ward, S. H., Hallof, P. G., Sill, W. R., and Nelson, P. H.: Mineral discrimination and removal of inductive coupling with multifrequency induced-polarization: Geophysics, 43, 588609, 1978

Poulsen, T. G., Moldroup, P., Sørensen, K., and Hansen, J. A.: Linking landfill hydrology and leachate chemical composition at a controlled municipal landfill (Kåstrup, Denmark) using state-space analysis, Waste Manage. Res., 20, 445-456, doi:10.1177/0734242X0202000508, 2002.

Pryet, A., Ramm, J., Chilès, J.-P., Auken, E., Deffontaines, B., and Violette, S.: 3D resistivity gridding of large AEM datasets: A step toward enhanced geological interpretation, J. Appl. Geophys., 75, 277-283, doi:10.1016/j.jappgeo.2011.07.006, 2011.
Revil, A. and Glover, P. W. J.: Theory of ionic-surface conduction in porous media, Phys. Rev. B, 55, 1757-1773, doi:10.1103/PhysRevB.55.1757, 1997.

Revil, A. and Leroy, P.: Constitutive equations for ionic transport in porous shales, J. Geophys. Res., 109, B03208, doi:10.1029/2003JB002755, 2004.

Schön, J. H.: Physical properties of rocks: fundamentals and principles of petrophysics. Pergamon, New York, p. 583, 1996.

Siemon, B., Voß, W., Ibs-von Seth, M., Ullmann, A., and Pielawa, J.: Airborne Geophysical Investigations of CLIWAT Pilot Areas - Survey Area Vojens, Denmark 2009, Bundesanstalt für Geowissenschaften und Rohstoffe, 2010.

Slater, L. D. and Glaser, D. R.: Controls on induced polarization in sandy unconsolidated sediments and application to aquifer characterization, Geophysics, 68, 1547-1558, doi:10.1190/1.1620628, 2003.

Slater, L. D. and Lesmes, D.: IP interpretation in environmental investigations, Geophysics, 67, 77-88, doi:10.1190/1.1451353, 2002.

Sønderjyllands Amt: Forureningsundersøgelser ved Hørløkke losseplads, Statusnotat, Report written by Watertech A/S, 2007.

Sørensen, K. I.: Pulled Array Continuous Electrical Sounding, First Break, 14, 85-90, 1996.

Støvring Harbo, M., Pedersen, J., Johnsen, R. and Petersen, K. (Eds.): Groundwater in a future climate, the CLIWAT handbook, ISBN: 87-7788-265-2, http://cliwat.eu/xpdf/groundwater in_a_future_climate.pdf (last access: June 2012), 2011.

Tabbagh, A. and Cosenza, P.: Effect of microstructure on the electrical conductivity of clay-rich systems, Phys. Chem. Earth, 32, 154-160, doi:10.1016/j.pce.2006.02.045, 2007.

Tabbagh, A., Cosenza, P., Ghorbani, A., Guérin, R., and Florsch, N.: Modelling of Maxwell-Wagner induced polarisation amplitude for clayey materials, J. Appl. Geophys., 67,109-113, doi:10.1016/j.jappgeo.2008.10.002, 2009.

Titov, K., Komarov, V., Tarasov, V., and Levitski, A.: Theoretical and experimental study of time domain-induced polarization in water-saturated sand, J. Appl. Geophys., 50, 417-433, 2002.

Van Voorhis, G. D., Nelson, P. H., and Drake, T. L.: Complex resistivity spectra of porphyry copper mineralization, Geophysics, 38, 49-60, doi:10.1190/1.1440333, 1973.

Vanhala, H.: Mapping oil-contaminated sand and till with the spectral induced polarization (IP) method, Geophys. Prospect., 45, 303-326, 1997.

Worthington, P. F.: The influence of shale effects upon the electrical resistivity of reservoir rocks, Geophys. Prospect., 30, 673-687, 1982. 